\title{
Culturally Diverse Students in Higher Education: Challenges and Possibilities within Academic Literacy Practices
}

\author{
Elena Tkachenko, elena.tkachenko@hioa.no \\ Kari Bratland, kari.bratland@hioa.no \\ Jorunn Store Johansen, jorunn.johansen@hioa.no \\ Oslo and Akershus University College of Applied Sciences
}

\section{Keywords:}

culturally diverse students

teaching and assessing academic literacy skills

higher education

cultural differences

cultural awareness

dialogic approach to teaching academic literacy

intercultural communication 


\begin{abstract}
With growing diversity in the population, higher education faces a new situation with increasing student diversity. In our paper, we will explore questions concerning the consequences student diversity has for higher-education institutions. Based on our experience from three different $R \& D$ projects, the differences in culture and academic literacy practices give culturally diverse students challenges that have often been ignored in academia. Some other studies also document that this group of students has a much higher risk of dropping out and underachieving than majority students (Andersen \& SkaarerKreutz, 2007; Støren, 2009). In our paper, we are going to discuss the students' challenges and discourse of remediation that is often associated with their challenges and suggest how higher-education institutions can adjust their practices to be more oriented to intercultural communication. Intercultural communication as a dialogic approach may create dynamics in academic tutoring and lead to mutual change/transformation instead of a one-way adaptation of existing academic literacy norms. We argue that all teachers should be aware of cultural differences in literacy practices in the education systems and strive to adjust their teaching practices to the diversity in the classroom. This approach, we believe, can contribute to a better learning environment for all students, independently of their backgrounds.
\end{abstract}




\section{Introduction}

In higher education today, we find an increasing number of students whose native language is different from the language of instruction, and whose cultural experiences are different from those of mainstream students. The diversification of the student population is the result of two main developments: widening participation, which attracts students from for example immigrant backgrounds to higher education, and global student mobility as a result of more focus on internationalization of higher education (Wingate, 2015). In addition to culturally diverse students, there are a number of different terms used in the literature and research to refer to this student group, for example second language students (L2 students). In this paper, we will mainly use the term culturally diverse students, but we will also problematize the use of this term and discuss if it could be replaced by a more accurate term. In our article, we will take a closer look at the diversity of the student group, where we will let official statistics about the student population guide us to a more subtle picture of student diversity in higher education in Norway.

The major goal of this paper is to explore issues concerning the challenges multilingual classrooms constitute in academia and the possibilities they create for development of intercultural competence. Quite often when culturally diverse students are on the agenda, it is pointed out that they have a much higher risk of dropping out and underachieving than majority-language students (Andersen \& Skaarer-Kreutz, 2007; Støren, 2009). In our article, we will discuss critically why this can be the case, and whether the challenges this group of students meets are often taken for granted or even ignored in academia. Finally, we will discuss in what direction the academic institutions should move in order to negotiate and develop intercultural communication and competence, and what the pedagogical implications of our findings are.

One of the key theoretical concepts we are going to use in this paper is "literacy practices." This concept is central to our understanding of reading and writing as social phenomena. Barton and Hamilton (1998, p. 3) define literacy practices as "the general cultural ways of utilizing written language which people draw upon in their lives. In the simplest sense literacy practices are what people do with literacy." They define "literacy events" as observable episodes which arise from literacy practices, activities where literacy has a role. Barton and Hamilton further point out that the understanding of literacy practices in a culture involves values, attitudes, feelings, and social relationships. Whereas these definitions of literacy are about written texts, we suggest in this paper a broader understanding of "text" (Halliday \& Hasan, 1985), comprising written and oral texts (e.g., a conversation, a discussion, and an oral exam) as well as multimodal texts (e.g., a photo story and an oral presentation with the use of ICT tools). In this paper, we will analyze a number of episodes from literacy events and try to discuss them in order to reveal underlying literacy practices.

Following this introduction, we first provide a short overview of statistical data about student diversity in higher education in Norway. Then, we shortly describe the methodology used in our study, give a critical review of literature on academic literacy instruction for culturally diverse students, and present our analysis dealing with challenges and possibilities of the multilingual classroom in higher education. 


\section{Student Diversity in Norwegian Higher Education}

As pointed out in the introduction, two main developments have contributed to increased student diversity in higher education in many countries, including Norway: widening participation and student mobility / internationalization. Although these two developments produce two distinct student groups, neither of the groups is homogeneous. On the one hand, we find a group of international students who often come from Western countries and stay in Norway for a shorter period of time (1-2 semesters) through different exchange programs (such as the Leonardo da Vinci, Socrates, and Erasmus programs). The students in this category usually have educational backgrounds from their home institutions and to a certain extent may be top-score students who are chosen for participation in these programs. The educational backgrounds that these students have may in many respects be quite similar to the backgrounds average Norwegian students have. On the other hand, we find a group of students with immigrant backgrounds. This group may appear to be quite a complex assembly because of differences in country of origin, age, educational background, socioeconomic class, length of stay in Norway, and proficiency in the language of instruction. What the students in these two groups do have in common, though, is that they pursue their study in a language other than their native language, and for this reason, they are often referred to as second language students (L2 students) in the research. However, we do not perceive this term as unproblematic. First, the second is not always a precise description, as for many of these students, the language of instruction would be a third or a forth language they master. Second, the group itself that appears as a result of the use of the term is highly heterogeneous, and it is impossible to make any generalizations about the language proficiency of the group. Thus, there may seem little point in such an oversimplified categorization.

In spite of the fact that the students in this study were recruited to the projects on the basis of their status as L2 learners, that is that their native language was not Norwegian, we consider the term culturally diverse students to be a more accurate term than L2 students. By employing the term culturally diverse students in this article, we hope to open and widen our perspective on academic literacy practices, moving it away from language alone and over to cultural background and how it influences the students' learning processes. We see this as necessary, as literacy practices are not merely concerned with language but involve values, feelings, attitudes, and relationships (Barton \& Hamilton, 1998).

However, we see some immediate objections to the term culturally diverse students as well, for example the timely question "How is culture defined?" To some extent, we may all be defined as culturally diverse, for example by the differences between urbanity versus rurality or by the differences in socioeconomic background. Questions concerning the term culture deserve a more extensive discussion than we are able to give within the limits of this article; we will merely conclude that we choose to keep to the term culturally diverse students when referring to students with backgrounds from other parts of the world than where they are currently studying.

At the same time, we also find a range of other terms referring to this group of students, for instance immigrant students, used by Statistics Norway (SSB) in the official statistics on education in Norway. SSB defines immigrants as "persons born abroad of two foreign-born parents and four foreign-born grandparents" (http://ssb.no). The Norwegian Social Science Data Services (NSD) uses the term foreign students in their data and defines it as "persons with foreign citizenships" (http://dbh.nsd.uib.no). This means that the term culturally diverse student does not completely coincide with the terms immigrant student and foreign student because culturally diverse students can be born abroad or in Norway and in both cases have other cultural backgrounds than their fellow students, and a part of this group of students, especially those with immigrant backgrounds, may have Norwegian citizenships. At the same time, students with foreign citizenships may also have lived in Norway for 
many years already (and still have foreign citizenships). Regardless of this, we are still able to draw useful information from official numbers and statistics since these data will tell us something about the growing student diversity in higher education in Norway.

The statistics below (see figure 1) show the proportion of immigrant students (defined by SSB) in higher-education institutions in Norway from 2007 to 2011. The figure presents the overall percentage (top line) as well as statistics divided into two groups: the bottom line represents students who originate from Western parts of the world (EU/EEC, USA, Canada, Australia and New Zealand), and the middle line represents students with backgrounds from "non-Western" parts of the world (Asia, Latin-America, Oceania [except Australia and New Zealand], and Europe [except EU/EEC]). The figure shows that the first group constitutes the smaller part of the total amount of immigrant students, which suggests that most culturally diverse students in higher education in Norway have backgrounds from nonWestern parts of the world. The proportion of students in the first group has been quite stable over the years, only slightly increasing since 2008. On the other hand, the proportion of students in the second group (middle line) has been, and is, significantly increasing.

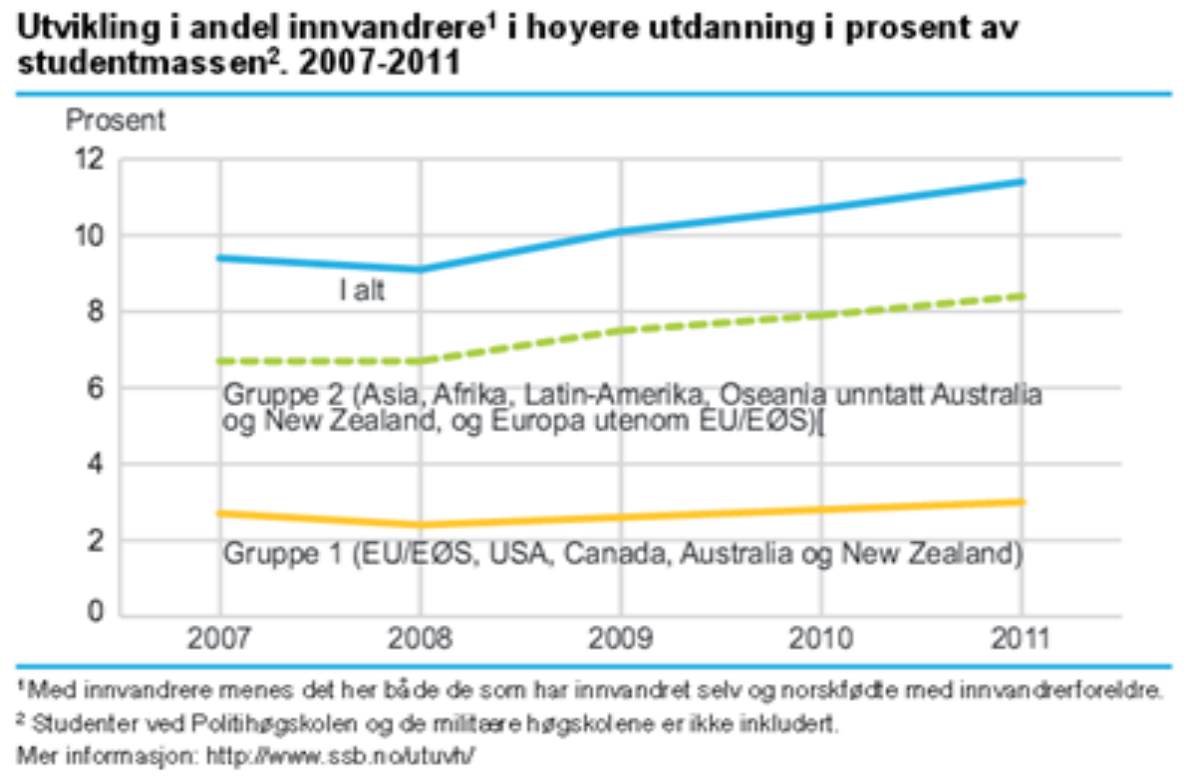

\section{Figure 1.}

Development in the proportion of immigrant students in higher education (percentage of the student mass) in Norway, 2007-2011.

Summing up these statistics, we can say that around $12 \%$ of the student population in Norwegian higher-education institutions originate from places outside Norway, and the largest part of this diverse student group have non-Western backgrounds. As a result of this increasing diversification, one may say, following Turner (2011, p. 8), that "nearly all students and all teachers in higher education, regardless of discipline, are also participating in intercultural communication, even if they do not always fully recognize it."

In the next section, we will discuss some theoretical perspectives on how higher-education institutions have dealt with this student diversity with regard to the challenges linguistically and culturally diverse students meet with regard to academic literacy and what pedagogical practices have been suggested to ensure that students from different backgrounds gain the necessary insight into the literacy practices of academia, which are new to them. 


\section{Theoretical Perspectives on Academic Writing and Literacy Practices}

Since language and writing are cultural phenomena, a person's experience with texts and literacy practices is culturally dependent. Students who come from different cultural traditions may have textual experiences that are different from those of majority students in mainstream academic culture in higher education, and their meeting with new literacy practices may be challenging for them because of the contradictions between the cultural norms and traditions that may arise. Academic writing as a discipline have for a while now discussed how higher-education institutions could deal with the challenges these students meet. Do they teach the students a set of skills and conventions considered necessary for academic writing and expect the students to adapt to the new communities of practice? To what extent is the academic community interested in the students' previous textual and literacy experiences and in how these can enrich the academic communities' existing literacy practices?

Canagarajah (2002) has discussed how different approaches to academic writing and English as a second language provide different answers to the questions above and either enhance or restrict culturally diverse students' possibilities for finding their voice in the academic literacy practices.

\section{English for Academic Purposes}

English for Academic Purposes (EAP) as a discipline has a long tradition in Anglo-American universities and has focused on describing features of academic texts in various genres and disciplines. These descriptions have further been used for pedagogical purposes in order to develop writing courses and teach students to apply these features and communicate effectively through their writing. In spite of EAP's valuable contribution to the understanding of features and genres of academic discourse and good pedagogical intentions to reveal and teach norms for academic writing, Canagarajah (2002) criticizes this approach for its normative view on academic discourse and literacy practices and its instrumental orientation of writing pedagogies. The challenge here is that academic discourses are positioned as something established once and for all, and there is no space for questioning or negotiating the established norms and features. If a culturally diverse student does not follow the conventions, it is seen as a deviation or a sign of lack of proficiency or unintelligence. The established norms and conventions dominate, and the academic community tends to take them for granted without a critical evaluation. As a result, all alternative ways of writing or deviation from the established conventions are perceived as inferior or underestimated, making it difficult for culturally diverse students to bring other resources that they know from their previous writing experience to their writing.

\section{Contrastive Rhetoric}

Contrastive Rhetoric (CR) is another approach to academic writing. It is based on relativistic assumptions that different cultures have different conventions for texts and literacy practices (Connor, 1996; Connor, Nagelhout, \& Rozycki, 2008). The "father" of contrastive rhetoric, Kaplan (1966), studied texts written by learners with English as a second language and with different first languages. He found some particular cultural patterns in the way in which they organized their texts, which he claimed was the result of influence from the students' first languages. Texts in the European-American tradition usually have linear structure. The same do Russian and Roman languages, although with a great deal of digressions, that is passages that may seem irrelevant for the main idea. In contrast, texts in oriental languages like Japanese and Chinese tend to be structured in a circular way and express ideas more indirectly. Culturally diverse students are thus influenced by the literacy 
practices of their cultural communities, also when they write academic texts in their second language.

Contrastive Rhetoric writing pedagogy is aimed at making the students aware of different patterns in the texts from different cultural traditions and by this helping them become proficient in academic writing in their second language. Although this theoretical approach to academic writing, unlike the EAP approach, considers cultural differences in literacy practices, some researchers (Canagarajah, 2002; Kubota \& Lehner, 2004) criticize CR for being instrumental and diminishing the combination of different cultural traditions in the students' texts to be just cultural interference rather than an expression of creative writing processes or an attempt to negotiate established cultural traditions. Thus, CR has not gone a long way from the EAP approach and still relies on established norms expecting that culturally diverse students are supposed to leave their own cultural traditions and adopt the new ones in order to be accepted in the new linguistic community. Some other criticisms also concern the view of culturally diverse students as representatives of their cultures, lack of acknowledgement of the writer's agency (as the cultural influence lies outside of the writer's control), and essentialism since cultures are represented as something established and unchangeable. Later, CR has developed further (see, e.g., Conor et al., 2008) and become more oriented to academic writing as a social phenomenon rather than just looking at and comparing the organizational and argumentative structure of texts in different cultures.

\section{The Social-Practice Approach}

Focusing on academic writing as a social practice opens possibilities of an interchange between different literacy cultures and may provide good pedagogical opportunities to discuss, negotiate, and analyze discourses in different scientific and cultural traditions. Such an approach is a step forward from CR since it does allow one to look for similarities in literacy practices rather than highlight differences and to cross borders between cultural conventions. Participation in a social practice is not something established, but is dynamic and is constructed in each particular social act. As in other situations, it is possible for one person to be part of a number of social communities and to switch between different memberships in a number of different social situations. Although this view is much more flexible, Canagarajah (2002) discusses the unequal status of different literacy practices and conventions and problematizes to what extent this flexibility and multiple identity idea is acceptable in reality. Another problem might be that culture is understood as being something homogeneous.

\section{The Transculturation Model}

The issue of homogeneity is exactly what the Transculturation Model problematizes: the researchers following this theoretical approach underline that literacy practices are not homogenous and that it is thus impossible to characterize them as belonging to one particular culture (Zamel, 1997). Rather, they orientate to hybridity, highlighting that literacy practices are shaped by a mix of different cultural traditions. This approach gives culturally diverse students an opportunity to use their whole repertoire of different styles, conventions, and norms in their writing and move between discourse communities freely. Canagarajah (2002) points out that this can challenge the established dominating conventions in academia. However, this might not be an easy task, as Canagarajah (2002) points out, since academic communities still have quite strict gate-keeping practices and not much tolerance may be shown for divergence from standard requirements of academic writing, especially when it comes to academic publication practices or student assessment. 


\section{The Contact-Zones Approach}

The last theoretical approach to academic writing we will overview here is the contact-zones approach (Pratt, 1991). This theory emphasizes the writer's agency and opens up for opportunities to negotiate academic genres, especially critically negotiate dominating conventions. Such opportunities do not appear automatically - as opposed to what is the position of the Transculturation Model, one cannot just mix different conventions as one wants or just switch between them. But the students need to be aware of communication strategies that can be used in order to negotiate literacy practices and text conventions in a particular academic discourse successfully.

Further in the paper, we will discuss some particular literacy events observed in one of the higher-education institutions in Norway. In our analysis, we will try to find out what kind of writing pedagogies and conceptions of academic literacies they belong to. We will show how literacy practices belonging to the EAP or the CR approach are concerned with the challenges culturally diverse students meet in higher education without necessarily offering good solutions to these challenges. We will also demonstrate how more opened theoretical approaches give opportunities for negotiating intercultural communication. Before we go to the discussion of our data, we shortly present the methodology used to collect these.

\section{Methodology}

The background for this article is three R\&D projects which aimed at helping L2 students in mainstream educational programs in early-childhood education and care and youth- and healthcare-teacher education cope with challenges in their studies. As teacher educators, we were actively involved in these projects being tutors/supervisors for these students, thus both teaching/supervising the students, documenting our actions and collecting research data at the same time. Our work is thus grounded in action-research methodology (Tripp, 2005). Action research is usually described as practice-based research undertaken by those who participate in that practice. The aim of action research is quite often to change and improve the observed practice, and in educational contexts, this may often be to improve or make one's own teaching more effective or influence the students' learning (Tripp, 2005). In the implementation of our projects, we followed-up the students in the challenges they met in their academic studies. We have tried different approaches and initiated "actions/interventions" to help them cope with these challenges, evaluated the results, reflected upon the process and outcomes and tried again, constantly responding to the students' needs as they emerged. Thus, the research process can be characterized as cyclic, responsive, and emergent, like most action research (Tripp, 2005).

The first project, "Academic Writing with Norwegian as a Second Language," lasted for three years and was aimed at following up students in a workplace-based study program in earlychildhood education and care. Around forty students in six classes have been followed-up, and the actions initiated within this project also involved academic staff teaching the class. The documentation of the project involved tutor's log writing, observations, summaries of tutoring sessions and seminars, and student texts.

The second project, "Language in practice," was a development project where a new model for language tutoring was tried out, revised and redesigned, and then tried out again. The goal was to include the language used both in academia and in practice, both oral and written, for L2 students in a full-time early-childhood education program. The model was developed in the years between 2009 and 2011 and then implemented as a part of the study program. Every school year of this project, between nine and thirteen students asked for tutoring and became informants. The data and documentations consist of personal language portraits of the students, PowerPoint presentations of the model before and after the revision, summaries of evaluation workshops with students, and observations. 
The third project was initiated in the spring semester of 2014 as an offer to culturally diverse students attending the bachelor program for youth- and healthcare-teacher education. The aim of the project was initially to give students extra training and support in the Norwegian language, but it developed into something more than just a language course. The tutor explored areas of the bachelor studies that the students found challenging and aimed at seeking solutions together with the students. Eight students were invited to attend tutoring/classes. The documentation of the project involves observations, student texts, and tutor's notes.

Based on our work with these three projects, we have chosen several episodes from tutoring sessions with our students that we will use here for our analysis. We use them to reveal and discuss literacy practices that are taken for granted in the mainstream highereducation culture and to illustrate what possibilities these situations can give for the whole classroom with regard to intercultural competence.

\section{Cultural Differences in Academic Literacy Practices: Challenges and Possibilities in a Multilingual Classroom}

Following Turner (2011), we intend to show through our analysis of literacy events how language is made invisible in higher education and in which contexts the remediation discourse appears to make the language a problem. Along with this, our examples will also demonstrate the invisibility of the culturally diverse students' competence gained from other sources than the mainstream culture.

\section{Example 1 from a tutoring session:}

An L2 student in early-childhood education comes to tutoring, frustrated. She says that she was told that mistakes in spelling and grammar do not really count much. The lecturers always underline that content is more important. Therefore, she decided to focus on content in one of her assignments. In the writing process, she was in dialogue with her teacher about the text and handed it in several times, still focusing on the content. But when handing in the final assignment, she failed due to the fact that the language in the text was difficult to understand. The student feels frustrated and misled. She wonders why the teacher did not give her guidance on the language part, so that she would have been given a chance to pass.

As we see in this episode, the teacher in her tutoring does not consider it her responsibility to comment on the student's language, as language is considered less important than the content of the student's text, the latter being the only theme of the supervision sessions and feedback. In spite of this, language turns out to become an important criterion for assessment. This example illustrates what Turner (2011, p. 24) calls invisibility of language in higher-education practices: "The centrality of language use in academic success tends to be ignored. When language becomes visible, that is, when attention is drawn to it, this can only be because it has not been used 'properly'." This episode is an example of such a practice: the role of language is diminished in the supervision, but it becomes visible in the assessment of the student's essay when language is not properly used.

Teachers of culturally diverse students in higher education often express that the students have not received enough language instruction to meet the requirements in the classes (Zamel \& Spack, 2004). We have often experienced similar attitudes and essentialist views of language among academic staff in our projects, where language is understood to be an isolated skill that academic staff consider necessary in order to start the studies in higher education. As Zamel (1998) points out, such a view releases faculty from the duty to take language into account when they teach their disciplines. A similar position is advocated by 
the student's supervisor in this episode. Wingate (2015, p. 58) points out that there might be several reasons for the subject teachers' unwillingness to incorporate language aspects in their teaching: workload and time, the teachers' beliefs that L2 students should learn the language before they start their university studies, as well as lack of knowledge of how to teach academic language and literacy conventions since they have not been taught this themselves and their knowledge of the discipline discourses is to a large extent tacit and unarticulated.

Looking at these perspectives, we can see a gap between teaching and assessment practices. Another possibility could be that the teacher drew too much attention to language. Jonsmoen (2008, p. 53) describes this too as a usual scenario: "There is a tendency that both students and lecturers focus on the formal weaknesses of the text. This could make the students believe that language is more important than content." Our experience shows that this view is supported also by the students themselves: grammar and vocabulary instruction was what they expected from courses on academic writing or other similar support initiatives in the beginning. However, our experience demonstrates that the students' needs are more complex than just a language course. In supervision sessions and in courses, they often ask about how to structure a text, how to read and understand academic texts, and how to use language in the academic setting. This brings out a broader perspective on the challenges this group of students face. The next episode provides an example of this.

\section{Example 2 from a tutoring session:}

The students were preparing for an oral exam, and together with the language tutor, they practiced this situation, the tutor pretending to be the examiner. The students talked about the curriculum relevant for the exam, and the tutor listened and asked new questions. Several times during this session, the students asked the tutor about what they said wrong:

- Student: Was that wrong?

- Tutor: No, no, I think it is right!

- S: When you look at me like that, I feel like I am saying the wrong thing.

- T: No, I just concentrate! What you are saying is very good, keep going.

- S: But you are staring at me as if I said something wrong?

- T: I look at you to show you that I listen and that I am engaged in what you say.

Then followed a conversation about what eye contact meant in different cultures. The students said they often found it uncomfortable with the direct way in which eye contact is made in Norway. To them, it was polite to look away when someone else spoke.

What we see here is that the people involved in the conversation have different experiences with eye contact and communication, probably because they come from different cultural traditions. The tutor, representing the mainstream academic culture in the institution, makes direct eye contact with the student to show her that she is paying close attention to what she is saying. The student, having lived most of her life in a different culture, conceives the eye contact differently. In her culture, looking away is polite, and looking someone straight into the eyes might be impolite, or at least uncommon. Her interpretation 
is that the only reason the teacher would look directly at her was if she was saying something wrong.

This example illustrates that the challenges of culturally diverse students may go far beyond traditional writing. This is not about differences in text structure in academic text, but still, it is about differences in literacy practices regarding oral exams, and this kind of challenges and potential misunderstandings could have serious implications for the students' exam results.

The discipline of EAP, describing features of academic texts, would not have helped this student because knowledge of how to write a good text that will get a good grade in academia could not have been put to use in this situation of only oral language use. Neither would knowledge of CR since that discipline too is mainly concerned with the way written texts are organized. Still, this paper having suggested a broader understanding of "text," the situation of the oral exam should be considered a very important academic genre, as interpreting and handling this genre in a good way would definitely improve the chances of success for the students. Even within the social-practice approach, there will be a focus on the written text since the object is the social act of writing.

Therefore, even if one aim of EAP and CR is to make cultural differences more visible, important knowledge of the communication situation of the oral exam remains invisible to the student in the example. Thus, she does not have the possibility of preparing herself for all the possible challenges and misunderstandings that may occur prior to the examination. This could be listed as another case of the invisibility of language use in higher-education practices (Turner, 2011), as the knowledge of the discourse is unarticulated.

What made this situation even more complicated was that the tutor (being one of the authors) was not aware of the cultural differences concerning eye contact and therefore was unable to make this a subject of the tutoring prior to this situation. The misunderstanding led to a discussion where both parties learned about cultural differences regarding eye contact. The tutor probably learned more than the student, who was somehow aware of the difference because she had experienced it in other situations in different ways. This illustrates the possibilities of a situation like this - discussions between tutors and students can lead to mutual learning and expanded horizons through negotiations of the genres as described in the contact-zones approach mentioned earlier. As Turner (2011, p. 8) puts it, "intercultural communication is happening live, in situ, between tutors and students, student and student, and as a result, taken-for-granted norms of rhetorical and social interaction are being put to the test."

The intercultural communication going on in this example is what makes it a situation with possibilities. In a classroom with many students or in a course where all the themes had already been set by the teacher and with little room for improvisation, this discussion with learning as an outcome would probably not have occurred. Turner also suggests that intercultural communication itself has a performative dimension, that it constitutes a global higher education (Turner, 2011). 


\section{Example 3 from a tutoring session:}

During tutoring, a student expresses frustration over the assignment for the term paper she is supposed to write in her bachelor program for youth- and healthcareteacher education. The tutor enters into a discussion with the student:

- Student: I feel very insecure about how to write the term paper. I feel I do not understand exactly what the assignment asks me to do.

- Tutor: Ok. Let's have a look at it. Can you describe a little bit closer what you feel is the problem?

- S: I feel it is a big mess. I know what the topic should be, but how do I know what I should include in the paper and what I should exclude? I do not know what to put where. And first and foremost: how do I include my experiences from practice?

- T: I think I see what you mean. It sounds like you have many ideas and thoughts without being able to see clearly where to put them. I think a good place to start is to take a closer look at the assignment itself to get a clearer picture of what it asks you to do.

- S: That sounds like a good idea.

- T: Let's do it together.

The tutor reads the assignment together with the student.

- T: Do you think you can identify the different parts of the assignment? Let's start with the first sentence.

- S: They ask me to describe and explain something ...

- T: I agree. What about the next part of the assignment?

- S: They ask me to discuss something and then to give examples from practice.

- T: I agree. I think we can say that this assignment has three parts: (1) describe and explain, (2) discuss, and (3) give examples from practice.

- S: That's right!

- T: Now, you said you had many thoughts and ideas. Let's get them written down.

The student then expresses thoughts and ideas, while the tutor writes them down on the board.

- T: You have many ideas that seem relevant to the topic of the assignment. You said you feel it's a mess. A way to get rid of mess is to clean up, right?

- S: Right.

- T: So, what can we do to clean up a mess of ideas?

- S: ... Categorize ...?

- T: That is a good idea! I will show you a method we can use to do exactly that. 
The tutor draws three boxes on the board, and puts the numbers 1, 2, and 3 in them, each number referring to parts of the assignment.

- T: Now we can try to clean up by sorting out your thoughts and ideas into the boxes. What do you think about this first one, should it be in the box for describing/explaining, in the box for discussing, or in the box for examples?

- S: I think it should go in the first box. I think I should start with explaining what this is and then move on to discussing ...

The student and the tutor discuss all ideas and put them in boxes.

- T: Ok, now we have three boxes filled with ideas. It seems that we have managed to do some organizing?

- S: Yes, it really does. I feel it's all so much clearer to me now.

- T: I'm glad! This is a method that you can use in all future assignments if you feel it works for you. If not, we can try a different one next time.

- S: Thank you! But what about the third box, where we put my examples from practice? Should this be a separate part of the paper, or should I rather integrate the examples into the discussion?

- T: What do you think will be best?

- S: To merge the examples with the discussion.

- T: Then you should try to do that. If you feel that this is something that works for you and for the text itself, then stick to it. If not, try to put them in a separate part of the paper.

The tutor and the student go on to discuss what could be considered main topics and subtopics and also where it would be wise to get sources to back up statements, facts, and statistics. They also look at possibilities for not including all ideas and thoughts in the paper but rather to focus on a few of them.

This scenario shows that a tutoring session that was supposed to be solely about language teaching developed into being something more: a tutoring session concerned with discipline-specific discourse, genre conventions, and academic writing. As pointed out in example 1 above, students' needs are more complex than just a separate language course. In working with a specific assignment given to the student in one of the courses, the tutor aimed at connecting tutoring in the language and in discipline-specific discourse instead of following the original plan for language-support class. Also, the tutor aimed at keeping away from a normative view on academic discourse, such as that which we find in the EAP tradition. The tutor employed a dialogic approach by entering into a discussion with the student instead of telling her what to do - more along the lines of the social-practice approach. However, it is not certain that the tutor succeeded in achieving her goal, as communicating the established conventions of an academic discourse might always be perceived normative by the student.

The tutor in this example aimed at combining a focus on discipline-specific discourse, genre, academic writing, and language, thus providing a meaningful context for the academic norms that were being discussed. This might be a good approach according to Dysthe, Hertzberg and Hoel (2010, p. 10): "Academic writing is about 'writing yourself into' a discipline-specific discourse. It is not enough to have broad knowledge in the discipline, you 
also need to be able to express the knowledge" (our translation). Dysthe et al. (2010) argue that students are able to get into discipline-specific discourse only by expressing the obtained knowledge in their own words. Disconnecting language training from the context where it is supposed to be used will remove an opportunity for the students to practice ways of expressing themselves within the discipline-specific discourse. That it is important to be able to master the genres that are typical for a discipline and that academia often fails to make the established text conventions in the various academic discourses explicit/transparent to the students is another point made by Dysthe et al. (2010) One example that is given, is that in teacher education, a dominating text convention is that the students are expected to be able to integrate experiences from practice into theory in their written assignments. At the same time, exactly how to do this is often invisible or not made explicit in many of the disciplines.

The example from the tutoring session described above (example 3 ) shows that one of the main aspects the culturally diverse students often struggle with is how to integrate experiences from practice into theory. When the tutor enters into a dialogue with the student, she hopes to evoke an awareness in the student about where it would be most suitable to place the student's own experiences from practice in the paper. When asked by the tutor to suggest ways to integrate the examples into the text, the student suggests merging the examples with the theoretical part of the paper. The tutor then replies that this could be one way of doing it and encourages the student to try this solution. By not telling the student what to do or what not to do but trying to encourage the student's own reflection by dialogue and discussion, the tutor tries to be as little normative as possible.

Some of the experiences we had and our findings from our projects were quite surprising. Learning a new language in academia seemed to be much more complex and complicated than we expected, and language tutoring has many dilemmas. The situation where one tries to teach norms and at the same time sees norms as flexible and open for discussion is one of them. The question of where language ends and culture begins is another. Further in the paper, we will discuss possibilities for strengthening intercultural communication in the multilingual classroom.

\section{Pedagogical Implications: Strengthening Intercultural Communication in the Multilingual Classroom}

When students discover that their own notions of text norms do not match expectations in academia, they are in a dilemma: should they adapt to the standards that apply in the academic community, or will that be too much of a compromise of identity? It is important that teachers and supervisors be aware of this dilemma. Different theoretical approaches take different positions when it comes to this issue.

The pedagogical aim of CR is to make the students aware of the different patterns found in texts from different cultural traditions in order to make it easier for them to develop strategies to write as expected in an academic environment. This is a similar view to that which the EAP (English for Academic Purposes) tradition stands for, namely that students must learn and adapt to academic literacy practices in a given academic field (Canagarajah, 2002). Thinking within such approaches may have some consequences that we see as undesirable. If we put great emphasis on teaching students the literacy practices applicable in our context, we could be in danger of communicating that our literacy practices are the only correct ones and expressions from other cultural traditions are just disturbing and wrong. It will then be difficult to accept texts and literacy practices that do not follow established conventions. As a consequence, there will be no room for untraditional students, who may bring with them practices from other contexts or experiences. 
The transcultural model (Transculturation Model) discusses, as mentioned earlier, how texts in various professional circles show mixing of different traditions (Zamel, 1996, 1997). Based on this reasoning, it should be possible for students to combine their different identities in academic texts. This could enrich academic discourses and make them more inclusive. An approach like that gives students the opportunity to use everything they know while studying and also challenge some established conventions that dominate in an educational institution. Then, students are not required to "enroll" in a dominant environment. It opens up their opportunities to express themselves freely, be creative when making texts, and thus use all the resources they have. The problem with this model is the dominant conventions, for as Canagarajah (2002) points out, the academic community still has strict genre requirements, for example for exams and assignments that are being marked. If a student hands in something different from the well-established norm, she risks failing or being less successful.

Thus, we believe in communicating norms for different texts clearly to the students. Since the student texts are graded, we must deal with some criteria, norms, and standards. But examples of assignments and "templates" must not be presented to students as normative. Lillis (1997, p. 187) writes that such guidelines are mostly meaningless if they are not followed by an individual, detailed discussion connected to each student's own writing. It is important to provide the space in the education institutions to discuss norms and to negotiate and find flexible solutions. This can be done in teaching, in student council, or in language tutoring, and it should also be done among teachers.

Language tutoring could, if successful, be a form of intercultural communication (Turner, 2011). In this communication, similarities and differences will emerge. Turner (2011) believes that through intercultural communication, academia with all its ancient traditions and norms starts moving almost automatically, and reflection occurs. It is important that we be open to reflection on the practices we have. Such openness can lead to interesting discussions about what a good text is and raise awareness among both teachers and students. Unlike the other approaches we have mentioned, dialogue leads to mutual change, not adaptation. The norms should thus not be firmly established but rather be the subject of further dialogue and constant evolvement. Grading practices should also be subject to dialogue about what criteria to apply. Faced with students who come from a different culture, we have an opportunity to look at our own with new eyes and to be critical and willing to change. This is an opportunity we should not miss. We do not believe, however, that the process of intercultural communication, dialogic practices, transparency, and mutual change will go automatically. To achieve an academic field with high quality, we need to be aware of what a resource dialog can be - and learn to use it in a good way. Here are some examples of possible forms of work which in our experience can create dialogue:

- Verbal discussions based on the reading of literature or situations from practice, with the lecturer and/or fellow students

- Discussions about written work with students

- Oral-presentation exercises in small groups

- Dialogue about linguistic genres, oral and written, used in academia and/or the practice field

- Dialogue about all the norms for literacy practices taken for granted in academia and the practice field 


\section{Conclusion}

In this article, we have taken a closer look at the diversity we find in higher-education institutions in Norway today. We have pointed to the fact that the student population does not constitute a homogenous group but in fact a highly heterogeneous one. Culturally diverse students face different challenges in Norwegian academia today. We have explored different theoretical approaches to questions concerning academic literacy practices, and by referring to some of our experiences from teaching and tutoring culturally diverse students, we have explored different challenges and possibilities cultural diversity brings to academia.

Another claim that we have made in this paper is that attitudes to culturally diverse students often bring a compensatory perspective / remediation discourse, where the challenges experienced by the staff focus on how to teach these students the literacy conventions in their second language and get them to adopt mainstream academic culture and literacy practices. We wish to problematize such attitudes and propose a more inclusive perspective, where one can add new literacy practices to the students' previous knowledge and experience rather than trying to replace it with the literacy practices of the majority community. This new perspective can also help one see the existing literacy practices in a critical light and renew and transform them to adapt to intercultural communication. In the three R\&D projects we rely on in this paper, the dialogic approach has proved successful in revealing cultural differences in literacy practices and was an important tool for negotiating and establishing common understanding of academic literacy norms. This approach, we believe, can contribute to a better learning environment for all students independently of their background. It can also be relevant in the students' further careers, in working life, and in professional communication with clients, colleagues, and so forth since the dialogue promotes critical thinking and cultural awareness, which are important aspects of intercultural competence in today's globalized world.

Further research should be done in order to evaluate the effect of dialogic approaches in teaching academic writing, and higher-education institutions should further review their practices for language teaching for culturally diverse students. 


\section{References}

Andersen, I. M., \& Skaarer-Kreutz, R. (2007). Forskjeller i karakterer og gjennomføring ved HiO. [Oslo]: Høgskolen i Oslo, Studieseksjonen.

Barton, D., \& Hamilton, M. (1998). Local literacies: Reading and writing in one community. London: Routledge. http://dx.doi.org/10.4324/9780203448885

Canagarajah, S. (2002). Multilingual writers and the academic community: Towards a critical relationship. Journal of English for Academic Purposes, 1, 29-44.

http://dx.doi.org/10.1016/S1475-1585(02)00007-3

Connor, U. (1996). Contrastive rhetoric: Cross-cultural aspects of second-language writing. Cambridge: Cambridge University Press.

http://dx.doi.org/10.1017/CBO9781139524599

Connor, U., Nagelhout, E., \& Rozycki, W. V. (2008). Contrastive rhetoric: Reaching to intercultural rhetoric. Amsterdam: John Benjamins.

http://dx.doi.org/10.1075/pbns.169

Dysthe, O, Hertzberg, F., \& Hoel, T. L. (2010): Skrive for å lære (2. utg.). Oslo: Abstrakt forlag.

Halliday, M. A. K., \& Hasan, R. (1985): Language, context and text: Aspects of language in a social-semiotic perspective. Geelong: Deakin University

Jonsmoen, K. M. (2008). Ikke en dag uten en linje: Skriving og minoritetsspråklige studenter i høyere utdanning. Norsk tidsskrift for migrasjonsforskning, 1, 45-62.

Lillis, T. (1997). New voices in academia? The regulative nature of academic writing conventions. Language and Education, 11(3), 182-199.

http://dx.doi.org/10.1080/09500789708666727

Kaplan, R. (1966). Cultural thought patterns in intercultural education. Language Learning, 16(1), 1-20. http://dx.doi.org/10.1111/j.1467-1770.1966.tb00804.x

Kubota, R., \& Lehner, A. (2004). Toward critical contrastive rhetoric. Journal of Second Language Writing, 13, 7-27. http://dx.doi.org/10.1016/j.jslw.2004.04.003

Pratt, M. L. (1991). Arts of the contact zone. Profession, 91, 33-40.

Støren, L. A. (2009). Choice of study and persistence in higher education by immigrant background, gender, and social background. Oslo: NIFU STEP.

Tripp, D. (2005). Action research: A methodological introduction. Educacao e Pesquisa, 31(3), 443-466. http://dx.doi.org/10.1590/S1517-97022005000300009

Turner, J. (2011). Language in the academy: Cultural reflexivity and intercultural dynamics. Bristol: Multilingual Matters.

Wingate, U. (2015). Academic literacy and student diversity: The case for inclusive practice. Bristol: Multilingual Matters.

Zamel, V. (1996). Transcending boundaries: Complicating the scene of teaching language. College English, 6(2), 1-11.

Zamel, V. (1997). Toward a model of transculturation. TESOL Quarterly, 31, 341-352. http://dx.doi.org/10.2307/3588050

Zamel, V. (1998). Strangers in academia: The experiences of faculty and ESL students across the curriculum. In V. Zamel \& R. Spack (Eds.), Negotiating academic literacies: Teaching and learning across languages and cultures. New Jersey: Lawrence Erlbaum Associates.

Zamel, V., \& Spack, R. (Eds.). (2004). Crossing the curriculum: Multilingual learners in college classrooms. New Jersey: Lawrence Erlbaum Ass.. 


\section{Web pages:}

Statistisk sentralbyrå (Statistics Norway)

http://ssb.no/en/befolkning/statistikker/innvbef.

Norsk samfunnsvitenskapelig datatjeneste (Norwegian Social Science Data Services)

http://dbh.nsd.uib.no/dbhvev/student/utenlandske rapport.cfm?dep id=1 